\title{
Biopriming of Infected Carrot Seed with an Antagonist, Clonostachys rosea, Selected for Control of Seedborne Alternaria spp.
}

\author{
Birgit Jensen, Inge M. B. Knudsen, Mette Madsen, and Dan Funck Jensen
}

Department of Plant Biology, The Royal Veterinary and Agricultural University, 40 Thorvaldsensvej, DK-1871 Frederiksberg C., Copenhagen, Denmark.

Accepted for publication 16 January 2004.

\begin{abstract}
Jensen, B., Knudsen, I. M. B., Madsen, M., and Jensen, D. F. 2004. Biopriming of infected carrot seed with an antagonist, Clonostachys rosea, selected for control of seedborne Alternaria spp. Phytopathology 94:551-560.

An ecological approach was used to select fungal antagonists effective against the seedborne pathogens Alternaria dauci and A. radicina on carrot. Twenty-five and 105 isolates originating from cereal and carrot habitats were screened against the pathogens in planta, respectively. Irrespective of isolate origin, fungal isolates belonging to Clonostachys rosea controlled pre- and postemergence death caused by A. dauci and A. radicina as effectively as the fungicide iprodione. Isolate IK726 of C. rosea was used in biopriming a seed lot with $29 \%$ A. radicina and $11 \%$ A. dauci (highly infected), and a seed lot with $4 \%$ A. radicina and $7 \%$ A. dauci (low infection). Seeds were primed with water alone (hydropriming) or with addition of $C$. rosea IK726 (biopriming). The occurrence of $A$. radicina and $A$. dauci increased twofold and fivefold, respectively, during 14 days hydropriming, irrespective of the initial infection level. On highly
\end{abstract}

ABSTRACT infected seed, biopriming reduced the incidence of A. radicina to $<2.3 \%$ and that of $A$. dauci to $<4.8 \%$ while the level of both pathogens was $<0.5 \%$ on bioprimed seed with a low initial infection rate. In sand stand establishment tests, hydroprimed seeds had a lower healthy seedling stand than nonprimed seeds, mainly due to a high degree of postemergence seedling death. In contrast, biopriming resulted in a seedling stand that was better than that of both nonprimed and hydroprimed seeds. C. rosea IK726 multiplied fivefold to eightfold, and microscopic observations using C. rosea IK726 transformed with a green fluorescent protein (GFP) reporter gene showed that seeds were covered with a fine web of sporulating mycelium of $C$. rosea. The positive effect of biopriming on healthy seedling stand remained after 5 months of storage at $4^{\circ} \mathrm{C}$ and IK726 survived at high numbers on these seed. In this study, we demonstrated that biopriming with the biocontrol strain $C$. rosea IK726 facilitates priming of infected seeds without risking adverse effects on seedling establishment.

Additional keywords: bio-osmopriming, drum priming, Gliocladium roseum, shelf life.
Alternaria dauci (Kühn) Groves \& Skolko and A. radicina Meier, Drechs., \& E.D. Eddy (syn. Stemphylium radicinum (Meier, Drechs., \& E.D. Eddy) Neergaard) are both important seedborne pathogens, causing seed decay and damping-off in carrot (Daucus carota L.). In addition, leaf blight caused by A. dauci can be a major constraint to carrot production worldwide and black rot caused by $A$. radicina is especially damaging to stored carrots $(2,25,28,35)$. Fungicide seed treatments can control Alternaria pathogens on carrot seeds efficiently $(34,39,41)$, but the use of fungicides is increasingly restricted in Europe and not allowed in organic farming.

There are only a few examples of biological control of seedborne Alternaria pathogens in carrot. Seed treatment with an isolate of Bacillus subtilis (FZB Biotechnik GmbH, Berlin) improved seedling emergence from seeds artificially inoculated with A. radicina, but mainly at temperatures above $20^{\circ} \mathrm{C}(3,16)$. Chen and $\mathrm{Wu}(7)$, using seeds artificially inoculated with $A$. radicina, selected nine isolates after in vitro screening of 1,897 isolates originating from soils, carrot seeds, or taproots. The efficacy of the bacterium Burkholderia capacia, isolate 229, on plant emergence was as good as seed treatment with iprodione. On the other hand, Jahn and Puls (15) found no effect on seedling emergence after treatment with Pseudomonas strain W 24 on carrot seed naturally infected by Alternaria spp. However, strain W 24 was originally selected for biocontrol efficacy against soilborne plant

Corresponding author: B. Jensen; E-mail address: bje@kvl.dk

Publication no. P-2004-0408-01R

(c) 2004 The American Phytopathological Society pathogens. Furthermore, Hermansen et al. (12) found no effect on field emergence from seed naturally infested with $A$. dauci using the commercial biocontrol agents (BCAs) Mycostop (Streptomyces griseovirides) and T-22 (Trichoderma harzianum Rafai strain KRL-AG2). These strains also were selected for biological control of soilborne diseases. This emphasizes that isolates selected for efficacy against soilborne pathogens are not necessarily suited for control of diseases caused by seedborne pathogens.

An ecological approach for selection of effective antagonists has been superior for obtaining new commercial BCAs $(13,23)$. Following this approach, selected organisms should be able to function in the same environmental niches as that of the pathogen they are expected to control. Therefore, the potential antagonists are isolated from the growth habitats of the host plants. However, antagonists selected with the ecological approach for control of a seedborne disease in one crop might also lead to effective control of another seedborne disease, especially if the pathogens have a similar ecology and epidemiology.

Seed priming is used commercially in many horticultural crops, including carrot, as a tool to increase speed and uniformity of germination and to improve final stand under environmental stress conditions $(4,8,29,36)$. However, if seeds are infected or contaminated with pathogenic or saprophytic fungi, fungal growth can be enhanced during priming $(31,40)$, thus resulting in undesirable effects on plant health. Fungicides have been applied for elimination of microbial growth during priming processes (29), but have limited use as stated previously. Therefore, application of antagonistic microorganisms during priming (biopriming) could represent an environmentally friendly strategy for control of seedborne pathogens. Inoculation of seeds with BCAs in combination with priming has, in several cases, been reported to enhance and stabil- 
ize the efficacy of BCAs, but such approaches have been used mainly for control of soilborne diseases $(5,6,11,42)$.

The objective of the present work was to screen and compare the biocontrol efficacy of various strains isolated from cereal and carrot habitats against $A$. radicina and $A$. dauci. One isolate, IK726 of Clonostachys rosea, with high biocontrol efficacy was subsequently selected, and the effect of priming carrot seed with this antagonist on the incidence of $A$. dauci and $A$. radicina and on pre- and postemergence infection was investigated. Furthermore, the development of the fungal antagonist during and after the priming process was studied using a green fluorescent protein (GFP) transformant of $C$. rosea IK726.

\section{MATERIALS AND METHODS}

Seed material and fungal pathogens. Two naturally infected seed lots of carrot cv. Royal Chantenay Rola were used in the experiments. The infection level was determined by deep freeze blotter test (14). On seed lot 142568, infection percentages were $29 \%$ A. radicina, $11 \% \mathrm{~A}$. dauci, and $30 \%$ contamination with A. alternata. On seed lot 133087 , infection percentages were $4 \%$ A. radicina, $7 \%$ A. dauci, and $13 \%$ contamination with A. alternata. Germination percentages of lots 142568 and 133087 on filter paper were 55 and $86 \%$, respectively. Seed of the same cultivar (lot 142849) with less than 1\% Alternaria pathogens and a germination percentage of $85 \%$ were used for artificial inoculation in screening experiments. Seed were surface-sterilized in $1.5 \% \mathrm{NaOCl}$ (7) and inoculated with A. radicina isolate IK1926, which previously was isolated from a diseased carrot seedling. Spores of $A$. radicina were harvested from 14-day-old potato dextrose agar (PDA, Difco Laboratories, Detroit) cultures after filtration through three layers of cheesecloth. Spore suspensions were adjusted with water to $5 \times 10^{4}$ spores per ml. Seeds were inoculated by shaking $10 \mathrm{~g}$ of seed in a $40-\mathrm{ml}$ water suspension for $10 \mathrm{~min}$ at $150 \mathrm{rpm}$. Subsequently, seeds were air-dried overnight on filter paper in a laminar flow hood and stored at $4{ }^{\circ} \mathrm{C}$ until use.

Isolation and cultivation of fungal antagonists. Microorganisms were isolated from different carrot habitats by washing, plating, and particle filtration techniques. Isolations were made from (i) peels of three independent batches of stored carrots, (ii) freshly harvested carrots obtained from a carrot field trial in a conventional farming system and a carrot field trial in an organic farming system, (iii) seed coats of a seed lot infected with Alternaria spp., and (iv) hydroprimed carrot seeds. Three different media were used for isolation of fungi. Two were nutrient rich: PDA amended with $2.2 \mathrm{~g}$ of Triton X-100 per liter and $0.5 \mathrm{~g}$ of chloramphenicol per liter and potato carrot agar amended with $0.5 \mathrm{~g}$ of chloramphenicol per liter. The third medium was special low-nutrient agar (ADSA Micro) (33). Two media were used to isolate yeasts: acidified yeast media (YM), pH 3.7 (24), and osmophilic YM amended with $40 \%$ glucose, $\mathrm{pH} 4.5$ (24). In total, 211 isolates of saprophytic fungi and yeast were obtained. Of these, 105 isolates (avoiding duplicates or triplicates in taxa of unknown antagonistic properties) were tested in a plant bioassay with naturally infected seeds. For each screening experiment, the isolates to be tested were grown on PDA at room temperature for 14 days.

A group of isolates originating from cereal habitats that previously had shown antagonistic properties against seedborne cereal seedling diseases caused by Fusarium culmorum and Bipolaris sorokiniana (22) were tested in plant bioassays with naturally infected seeds and seed artificially inoculated with $A$. radicina, respectively. Twenty-six fungal isolates originating from bulk soil (12 isolates), barley straw (9), roots infected with $F$. culmorum (2), barley seed (2), and barley leaves (1) were recultivated from $-80^{\circ} \mathrm{C}$ agar plug freeze cultures on PDA for 1 week. Subsequently, 5-mm-diameter agar disks were transferred to new PDA plates and incubated at room temperature for 14 days, except isolates IK17 and IK194 which were grown for 21 days before use.
Dried formulations of BCAs. Several commercial biocontrol products were tested also: Promot (T. harzianum and T. koningii), $5 \times 10^{7} \mathrm{CFU} / \mathrm{g}$; Supresivit (T. harzianum), $2 \times 10^{9} \mathrm{CFU} / \mathrm{g}$; TRI003 (T. harzianum), $3 \times 10^{8} \mathrm{CFU} / \mathrm{g}$; GlioMix (Gliocladium catenulatum), $1 \times 10^{8} \mathrm{CFU} / \mathrm{g}$; and Subtilex MB600 (formerly Epic), (Bacillus subtilis), $5 \times 10^{10} \mathrm{CFU} / \mathrm{g}$. Dry formulations of the near commercial isolates $C$. rosea IK726 (18) and IK726d11, a gfp transformant of IK726 (26) also were included. Both dried peat-bran preparations of IK726 and IK726d11 $\left(4 \times 10^{8} \mathrm{CFU} / \mathrm{g}\right)$, and a dried clay preparation of IK726 $\left(2 \times 10^{9} \mathrm{CFU} / \mathrm{g}\right)$, were prepared according to Jensen et al. (19). All dried formulations were stored at $4^{\circ} \mathrm{C}$ until use.

Seed coating with antagonists. Fungal spores were gently scraped from PDA cultures in water and filtered through nylon mesh $(38 \mu \mathrm{m})$. All spore solutions were adjusted with sterile water to a density concentration of $1 \times 10^{7} \mathrm{CFU} / \mathrm{ml}$. Seeds were coated by shaking $1 \mathrm{~g}$ of seed per treatment with $4 \mathrm{ml}$ of the adjusted conidial suspension on a shaker (IKA Vibrax; IKA Works, Wilmington, NC) for $10 \mathrm{~min}$ at approximately $130 \mathrm{rpm}$. Subsequently, the seed were air-dried on filter paper for $1 \mathrm{~h}$ in a laminar flow hood before planting. For coating of seed with dry formulations of $\mathrm{BCA}$, amounts of the respective dry formulations of $\mathrm{BCA}$ resulting in $1 \times 10^{7} \mathrm{CFU} / \mathrm{ml}$ were suspended in sterile water and shaken for $1 \mathrm{~min}$ on a vortexer. Treated seed were subsequently coated and dried as described previously. Effects of antagonist treatments were compared with water treatment and with the chemical fungicide iprodione ( $20 \mathrm{ml}$ per $\mathrm{kg}$ of seed).

Hydropriming and biopriming. Seed of carrot lots 142568 and 133087 were imbibed in aerated water $(50 \mathrm{~g}$ of seed per $500 \mathrm{ml}$ of water) for $16 \mathrm{~h}$. Seed were surface-dried for about $1 \mathrm{~h}$, and the water content was determined whereupon portions of seeds were dried to predetermined moisture contents (MC) of 38 and $40 \%$. Thereafter, seed were incubated in plastic containers with two $1-\mathrm{mm}$ holes in the lid at $15^{\circ} \mathrm{C}$ for an additional 13 days. For biopriming with $C$. rosea IK726, the clay inoculum of IK726 was applied during imbibition of seeds ( $2.5 \mathrm{~g}$ of clay inoculum per $500 \mathrm{ml}$ of water) or the IK726 inoculum was dusted onto the seed after drying the seed $(0.01 \mathrm{~g}$ of inoculum per $\mathrm{g}$ of seed at $40 \%$ $\mathrm{MC})$. The MC during priming was tested after 7 and 14 days

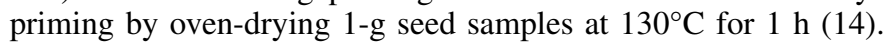
After priming, seeds were dried in a laminar hood overnight at $22 \pm 3^{\circ} \mathrm{C}$ to an $\mathrm{MC}$ of $7.8 \% \pm 0.2 \%$ before use in bioassays and blotter tests. Samples of hydro- and bioprimed seed were stored in airtight containers at $4^{\circ} \mathrm{C}$. Hydropriming and biopriming experiments were conducted three times for seed lot 142568 and twice for lot 133087.

Bioassay. Treated seed were sown in washed, coarse sand moistened with tap water $(3: 1, \mathrm{vol} / \mathrm{vol})$. Plastic boxes $(11 \times 17 \mathrm{~cm})$ were filled with $300 \mathrm{ml}$ of moist sand, and 50 seed were planted in 1-cm-deep holes and covered with $50 \mathrm{ml}$ of moist sand. Each treatment was replicated four times (in total, 200 seeds per treatment) and arranged in a fully randomized block design. Each block included a single replicate of each treatment and consisted of a tray that was covered with transparent plastic foil. Planted boxes were placed in a growth chamber at $20 \pm 1{ }^{\circ} \mathrm{C}$, with a $12-\mathrm{h}$ photoperiod at $200 \mu \mathrm{m} / \mathrm{m} / \mathrm{s}$ light intensity. Seedlings were watered after 8 and 14 days with tap water using a water atomizer. For screening bioassays, seedling emergence was recorded after 14 and 21 days, whereas in priming experiments, seedling emergence was recorded regularly from 5 to 28 days after sowing. Dead and wilted plants were removed and postemergence infection was confirmed by incubating the wilted plants on three layers of moistened filter paper. After 2 to 5 days incubation under near-UV light (NUV) with a 12-h light period at $20 \pm 1^{\circ} \mathrm{C}$, which allowed Alternaria spp. to sporulate, the plants were examined by dissection microscopy and all species of Alternaria were recorded. For the hydropriming treatments, seedling establishment of one set of samples was evaluated immediately after drying seeds to the 
predetermined MC (1 day priming), a second set after 7 days incubation ( 8 days priming), and a third set after 13 days (14 days priming). Furthermore, subsamples of stored seeds were evaluated in bioassays after 1, 2, 3, 4, and 5 months of storage at $4^{\circ} \mathrm{C}$.

Examination of Alternaria spp. on seed. The occurrence of Alternaria spp. on carrot seed during different steps of priming was assessed with a deep freeze blotter test (14). Samples were taken during the priming process at 1,8 , and 14 days priming. Seed $(40 \times 10$ seeds per treatment $)$ were incubated in petri dishes on moist filter paper for 3 days in darkness at $20^{\circ} \mathrm{C}$. Seed were subsequently kept at $-20^{\circ} \mathrm{C}$ for $24 \mathrm{~h}$ followed by incubation under $\mathrm{NUV}$ at $20^{\circ} \mathrm{C}$. The presence of $A$. radicina, A. dauci, and A. alternata on the seed was recorded under a dissection microscope (Olympus SZH; Olympus, Lake Success, NY) after 7 and 10 days

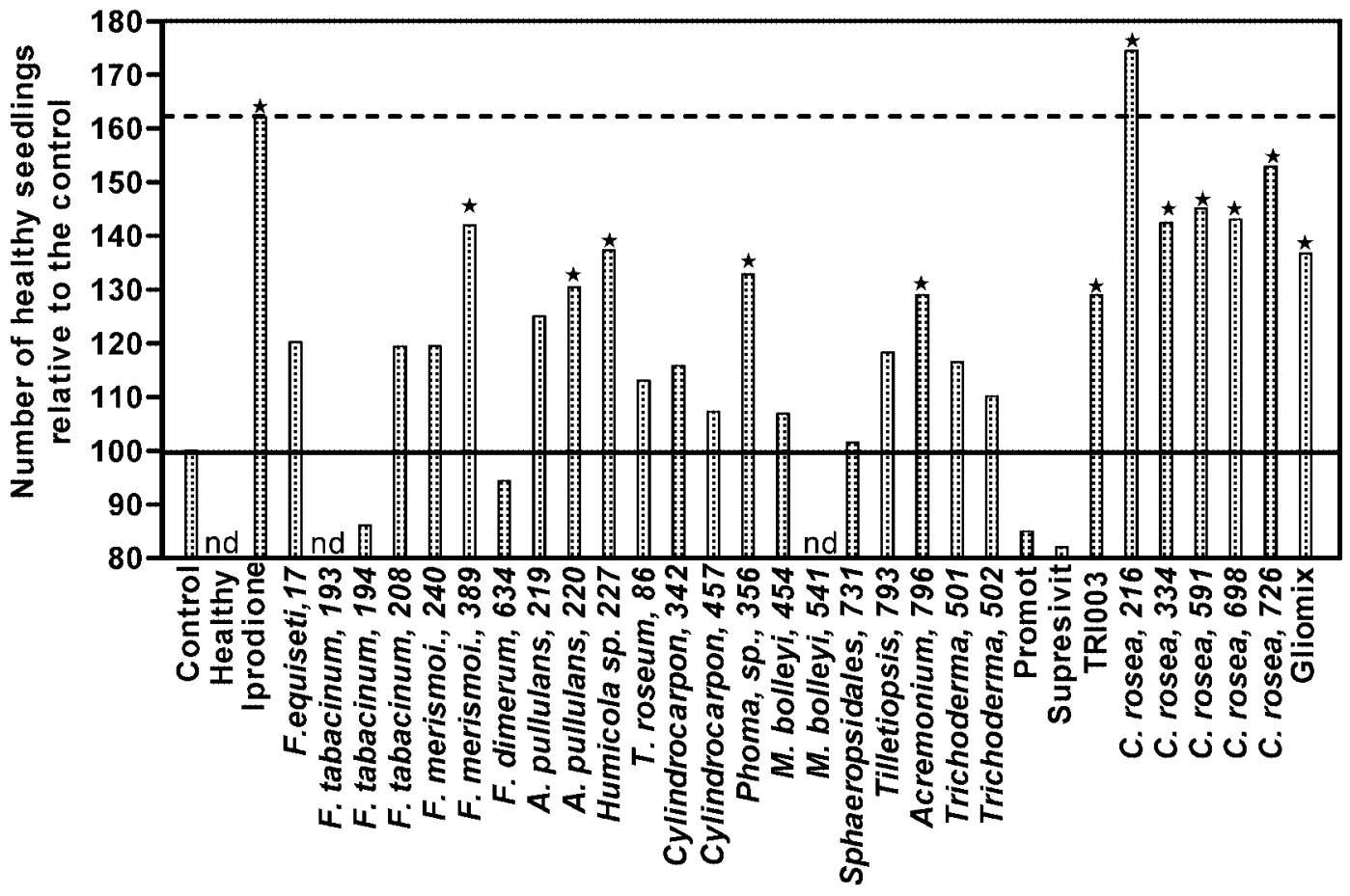

Treatment

Fig. 1. Screening of fungal isolates originating from cereal habitats. Spore suspensions were coated on carrot seeds naturally infected with Alternaria radicina and $A$. dauci. Emergence of healthy seedlings relative to the disease control (100, solid line) and the fungicide-treated control (162, dashed line) 3 weeks after planting in sand. Treatments marked with a $\star$ are significantly different $(P=0.05)$ from the water-treated disease control.

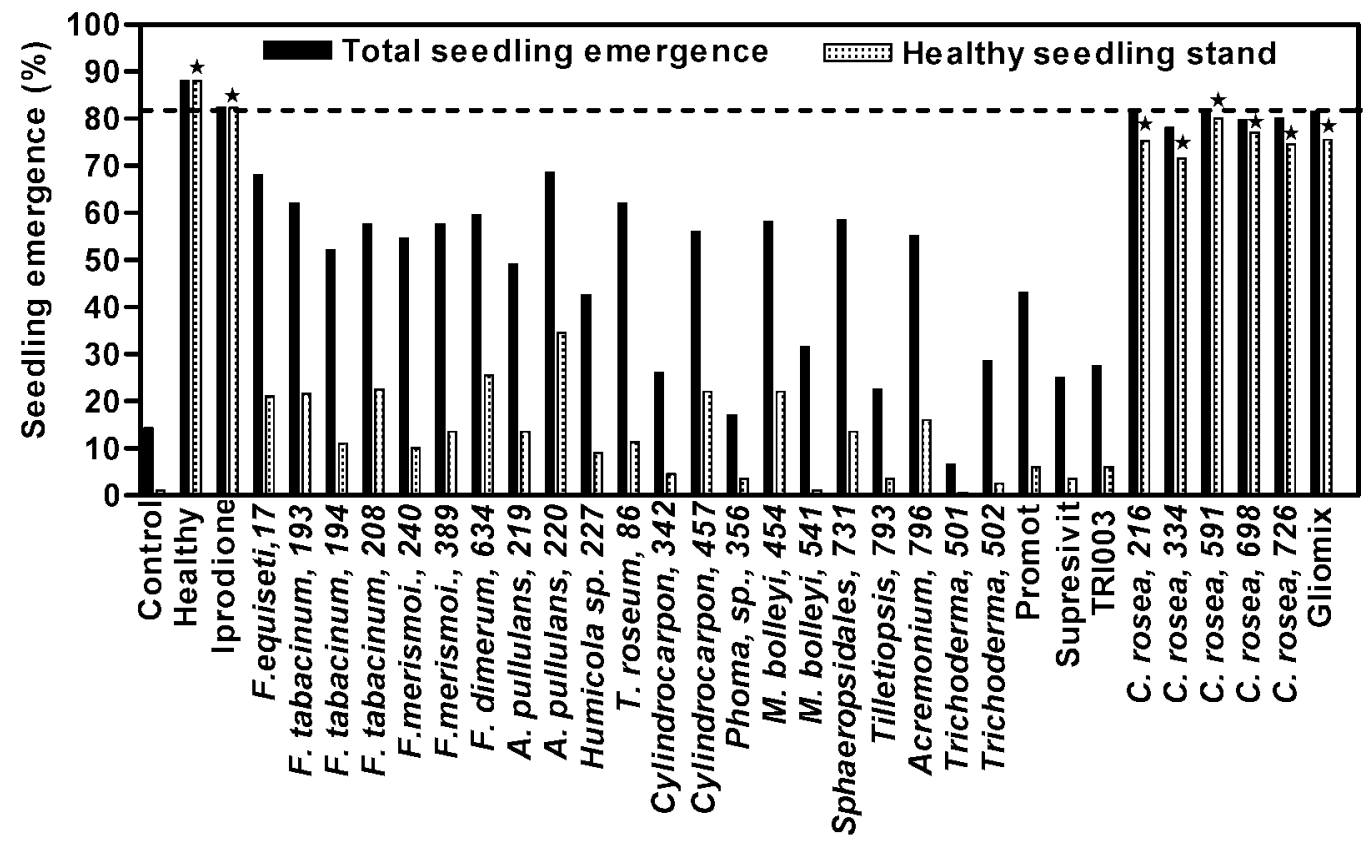

Treatment

Fig. 2. Screening of fungal isolates originating from cereal habitats. Spore suspensions were coated on carrot seeds artificially inoculated with Alternaria radicina. Total percentage of emerged seedlings and of healthy seedlings 3 weeks after planting in sand. Treatments marked with a $\star$ are not significantly different $(P=0.05)$ from the iprodione control. 
incubation. The occurrence of Alternaria spp. on seed was expressed as the percentage of seed where a fungal species was identified.

Monitoring the population of $C$. rosea on seeds. The population density of $C$. rosea on carrot seed was determined at 1- to 3-day intervals during the priming period. Subsamples of $3 \times$
20 seeds per treatment were shaken with $3 \mathrm{ml}$ of sterile water and 20 glass beads for $1 \mathrm{~min}$ on a vortexer at full speed. Serial dilutions of washing water were plated on PDA amended with chloramphenicol (0.5 g/liter) and Triton X-100 (2.1 ml/liter), and the plates were incubated at $20 \pm 2{ }^{\circ} \mathrm{C}$. Colonies were counted after 2 to 4 days, and the mean number of CFU per seed was calcu-

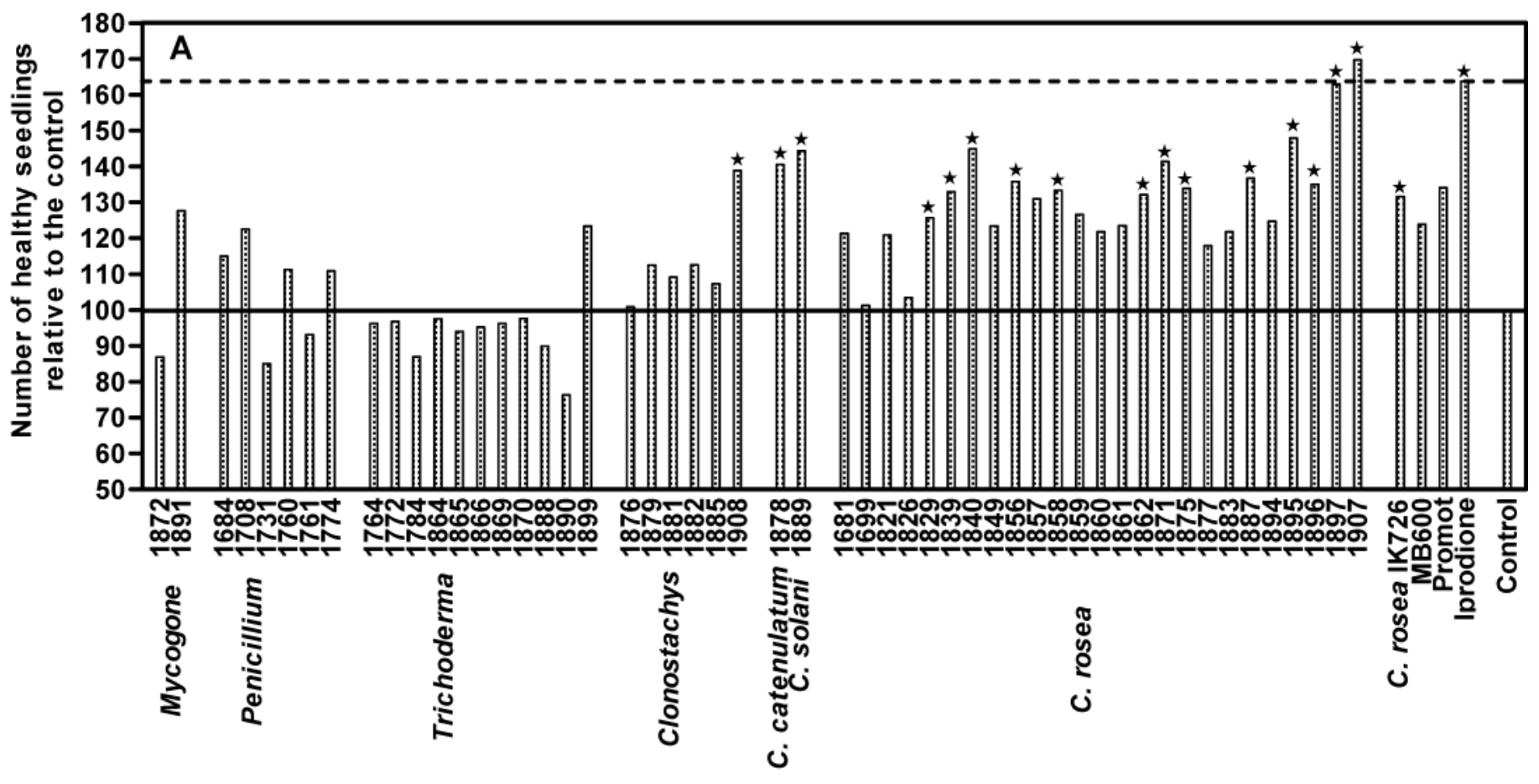

Treatment

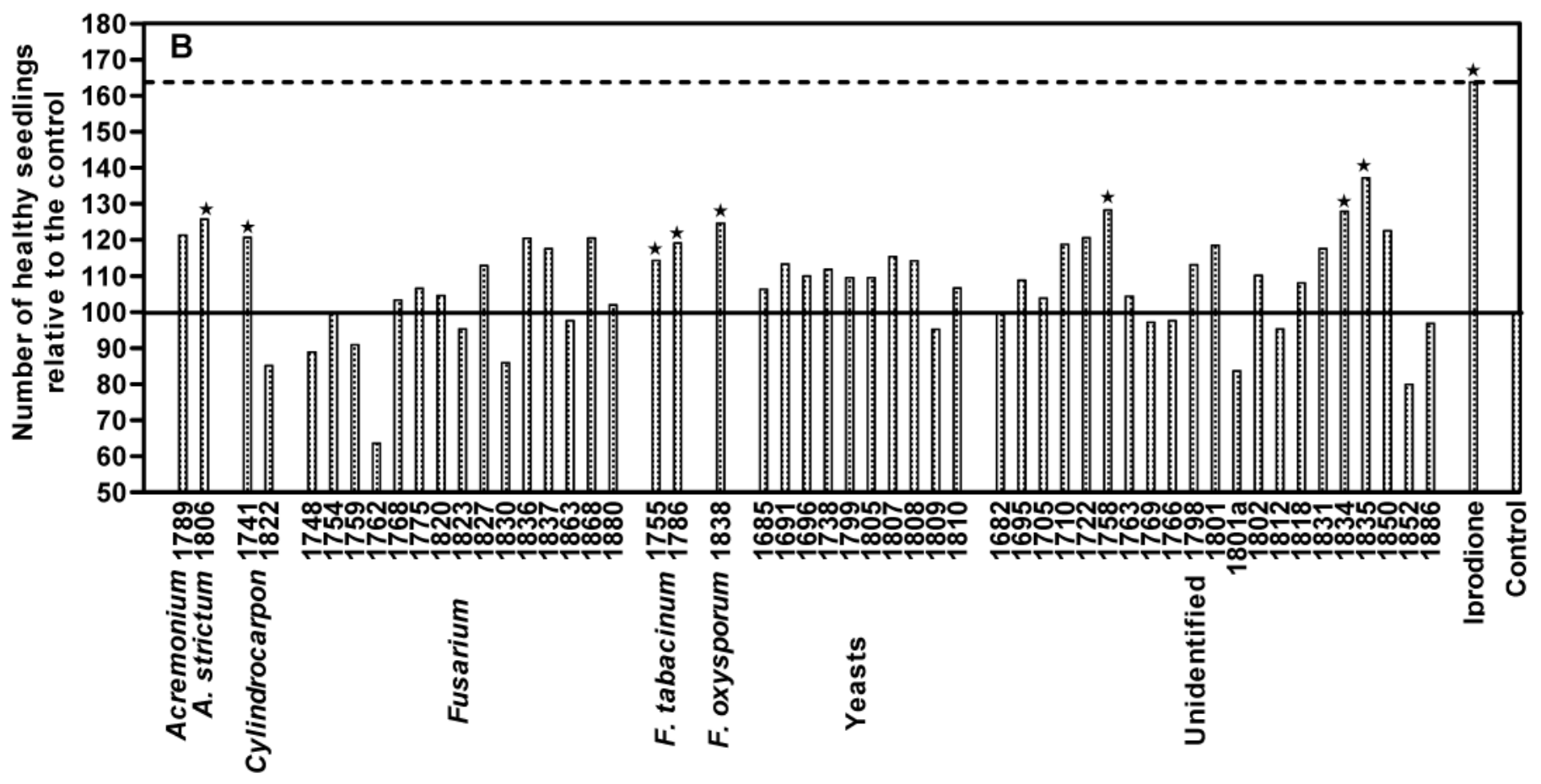

\section{Treatment}

Fig. 3. A and B, Screening of fungal isolates originating from carrot habitats. Spore suspensions were coated on carrot seeds naturally infected with Alternaria radicina and $A$. dauci. Emergence of healthy seedling 3 weeks after planting in sand. Treatments marked with a $\star$ are significantly different $(P=0.05)$ from the water-treated disease control. 
lated. The same method was used for evaluation of CFU on seed dried to $7.8 \% \pm 0.2 \% \mathrm{MC}$ and stored for $0,16,21,25$, and 37 weeks.

The growth and development of $C$. rosea on seed during priming was monitored using the $g f p$-transformed isolate (IK726d11) of biocontrol strain $C$. rosea IK726 (26). Seed were primed with a peat-bran formulation of $C$. rosea IK $726 \mathrm{~d} 11$ by dusting the formulation onto seed at a predetermined MC ( $0.1 \mathrm{~g}$ of IK726d11 per $\mathrm{g}$ of seed at $40 \% \mathrm{MC}$ ), as previously described. Seed primed with water only or with wild-type $C$. rosea were used as controls. Seed for microscopy examination, 30 at each time, were sampled immediately after application at day 0 and after 1, 2, 3, 4, 5, 7, 8, 11 , and 13 days (14 days of priming). Heavy mycelial growth and sporulation with verticilliate and penicilliate conidiophores were visualized with a stereo fluorescence microscope (SFM) (Leica MZ FLII; Leica Laser Technik, Heidelberg, Germany) equipped with a GFP 2 filter block with excitation at 480/40 $\mathrm{nm}$ and a barrier filter at $510 \mathrm{~nm}$ LP. Fine hyphal growth, spore germination, and individual spores were examined with an epifluorescence microscope (EFM) (Olympus BX 60) equipped with an MF filter block (455 to $495 \mathrm{~nm}$ excitation wavelength, mirror at $505 \mathrm{~nm}$, and barrier filter at 515 to $555 \mathrm{~nm}$ ) or a WIB filter block (460 to $490 \mathrm{~nm}$ excitation wavelength, mirror at $505 \mathrm{~nm}$, and barrier filter at 515 to $550 \mathrm{~nm}$ ) and by a confocal laser scanning microscope (TCS4d; Leica Laser Technik).

Statistics. Data were analyzed by analysis of variance and treatment means were compared with a least significant difference test at $P=0.05$. The bioassay for screening isolates included a maximum of eight antagonist treatments. The comparison of isolates was based on significant differences from the water and fungicide controls within each bioassay. The CFU data were $\log _{10^{-}}$ transformed before analysis of variance. Analyses were performed using the Statistical Analysis System (SAS Institute, Cary, NC).

\section{RESULTS}

Screening of fungal isolates. Among fungal isolates that previously showed antagonistic activity against $F$. culmorum and Bipolaris sorokiniana, 10 of 24 isolates significantly improved seedling emergence from seeds naturally infected with $A$. dauci and $A$. radicina (Fig. 1). The five $C$. rosea isolates and one isolate each belonging to Humicola, Aureobasidium pullulans, F. merismoides, Phoma, and Acremonium, respectively, had a biocontrol efficacy not significantly different from the iprodione control. When the same isolates were tested on seeds artificially infected with $A$. radicina, only the $C$. rosea isolates controlled pre- and postemergence infection of the pathogen as well as iprodione (Fig. 2). Several other isolates significantly improved healthy seedling stand, but not to the level of the healthy control and the fungicide control (Fig. 2). Of the commercial products, only TRI003 and Gliomix significantly increased emergence from naturally infected seeds (Fig. 1), but only Gliomix was as effective against artificial $A$. radicina infection as the iprodione treatment (Fig. 2). Of isolates obtained from carrot habitats, 24 of the 105 isolates screened significantly improved seedling emergence from seeds naturally infected with $A$. dauci and A. radicina (Fig. $3)$. Of the effective isolates, 13 belonged to $C$. rosea. The remaining isolates belonged to C. catenulatum (isolate 1878), C. solani (isolate 1889), Clonostachys sp. (isolate 1908), Acremonium strictum (isolate 1806), F. tabacinum (isolates 1755 and 1786), F. oxysporum (isolate 1838), Cylindrocarpon sp. (isolate 1741), and unidentified fungi (isolates 1758, 1834, and 1835). The biocontrol efficacy of isolates 1897 and 1907 of C. rosea was not significantly different from control provided by iprodione.

Effect of biopriming on occurrence of Alternaria spp. Hydropriming and biopriming of carrot seeds naturally infected with A. radicina, $A$. dauci, and $A$. alternata significantly affected occurrence of these pathogens (Table 1). After 8 days of hydropriming, the occurrence of $A$. radicina, A. dauci, and A. alternata on seed lot 142568 had each increased to more than $60 \%$. However, for both biopriming treatments, the occurrences of all Alternaria species were $<6 \%$ and furthermore were significantly lower $(P<0.0001)$ than the initial incidence of each species before biopriming. The occurrence of $A$. dauci increased fivefold after 14 days of hydropriming $(P<0.0001)$. In contrast, biopriming strongly suppressed Alternaria spp., as occurrences of all three species were below $4.8 \%$, which corresponded to a reduction in incidence of $\geq 94 \%$ of each Alternaria species compared with

TABLE 1. Results of blotter tests where the occurrences of Alternaria radicina, A. dauci, and A. alternata were recorded on two carrot seed lots hydroprimed and bioprimed with Clonostachys rosea IK 726 , at $15^{\circ} \mathrm{C}$

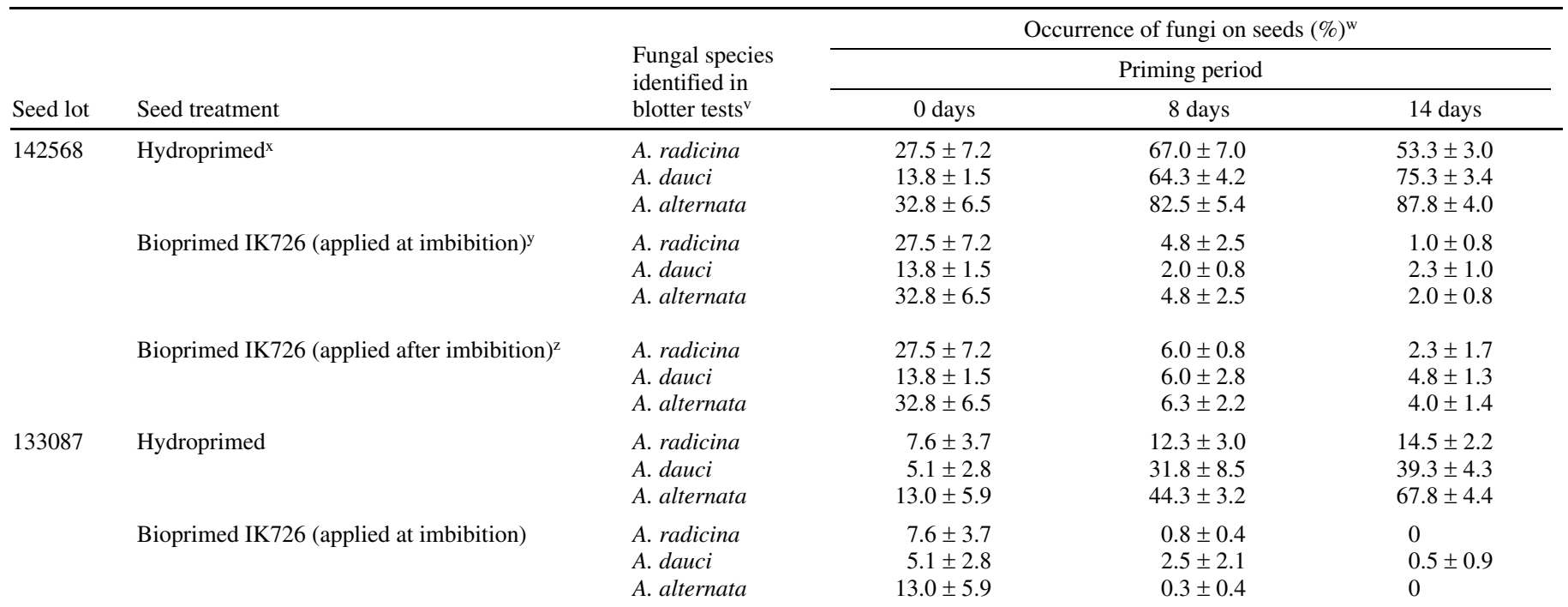

\footnotetext{
${ }^{v}$ A total of 400 seeds per treatment were incubated on moist filter paper at $20^{\circ} \mathrm{C}$ in darkness for 3 days, placed at $-20^{\circ} \mathrm{C}$ for $24 \mathrm{~h}$, and subsequently incubated at $20^{\circ} \mathrm{C}$ under near-UV light for 7 days.

${ }^{\text {w }}$ Mean percentage of seeds where A. radicina, A. dauci, or A. alternata occurred. Mean values are from four replicates \pm standard deviation.

${ }^{x}$ Seeds were imbibed in aerated water $(50 \mathrm{~g}$ of seed per $500 \mathrm{ml}$ of water) for $16 \mathrm{~h}$, dried to a predetermined moisture content (MC) of $40 \%$, and subsequently incubated at $15^{\circ} \mathrm{C}$. The procedure was also used for biopriming seeds.

${ }^{y}$ Clay inoculum of IK726 was applied at imbibition of seeds ( $2.5 \mathrm{~g}$ of clay inoculum per $500 \mathrm{ml}$ of water) before drying seeds to $40 \% \mathrm{MC}$.

${ }^{\mathrm{z}}$ Clay inoculum of $C$. rosea IK726 was dusted onto seeds ( $0.01 \mathrm{~g}$ per g of seed at $40 \% \mathrm{MC}$ ) after seeds were imbibed and dried to $40 \% \mathrm{MC}$.
} 
hydroprimed seeds. For seed lot 133087, which had a substantially lower infestation rate, a similar result was obtained. The occurrence of $A$. radicina increased twofold during hydropriming, whereas that of $A$. dauci increased about eightfold. In contrast, biopriming almost eradicated the three Alternaria spp.

Effect of biopriming on seedling emergence. Seedling emergence was affected significantly after 1,8 , and 14 days of hydropriming or biopriming (Table 2). When seeds were primed for 1 day, the initial emergence of primed seeds was as high as for nonprimed seeds. However, in the standard priming treatment, about one-third of the emerged seedlings subsequently died due to postemergence infection, resulting in a final seedling stand of $32.5 \%$. Priming of carrot seeds with water for 8 and 14 days affected the establishment of carrot seedlings even more (Table 2 ). Thus, although the total emergence was about $30 \%$, postemergence death reduced the final seedling stand to $7 \%$. In contrast, biopriming resulted in more than $46 \%$ of emerged seedlings and more than $43 \%$ of healthy seedlings, irrespective of the method for application of $C$. rosea IK726. Priming treatments affected seedling emergence of seed lot 133087 in a similar manner (data not shown), although the negative effect of hydropriming was less dramatic due to the lower Alternaria infestation level. Based on examination of wilted and dead seedlings from 14-day primed seed, infection by A. radicina and A. dauci corresponded to 24.3 and $43.3 \%$ of the total number of emerged seedlings, respectively (Fig. 4). For bioprimed seed, 1.8 to $6.5 \%$ of emerged seedlings were infected by $A$. radicina, whereas 2.3 to $6.5 \%$ were infected by $A$. dauci (Fig. 4). All dead seedlings from nonprimed seeds (9.8\% of emerged seedlings) were infected by A. radicina.

Effects of biopriming on seed storage. Speed of emergence and seedling establishment of stored bioprimed seed were evaluated during a 5-month period and compared to that of nonprimed seed (Fig. 5). Both primed and bioprimed seeds started to emerge after 5 days in the sand bioassays. At this time, no emergence was observed from nonprimed seeds (Fig. 5B). In addition, maximum stands of healthy seedlings were achieved approximately 7 days after sowing in the priming treatments. In contrast, less than $70 \%$ of the seedlings had emerged from nonprimed seeds at this time. Healthy seedling stand after biopriming treatments stabilized between 50 to $60 \%$, irrespective of the storage period (Fig. 5A to D), whereas postemergence death resulted in less than $20 \%$ of healthy seedlings during 5 months of storage of seed primed without $C$. rosea $\mathrm{IK} 726$.

Multiplication of $C$. rosea IK726 during priming. After application of IK726 to seeds either through imbibition of seeds or after drying seeds to 38 or $40 \% \mathrm{MC}$, the initial density of C. rosea varied between $0.7 \times 10^{4}$ to $1.2 \times 10^{4} \mathrm{CFU}$ per seed (Fig. 6). During the first 2 to 3 days of priming, the population density decreased significantly $(P<0.0001)$ for all biopriming treatments. However, the densities increased significantly 5 days after seed inoculation, with the best result for biopriming at $40 \%$ MC. At the end of biopriming at day 14, the antagonist had further multiplied on the seeds as both of the $40 \% \mathrm{MC}$ treatments had about $5.5 \times 10^{4} \mathrm{CFU}$ per seed while the $38 \% \mathrm{MC}$ treatment had $4.5 \times 10^{4} \mathrm{CFU}$ per seed (Fig. 6).

Survival of $C$. rosea IK726 after storage of primed seeds. After drying seeds to $8 \% \mathrm{MC}$, the population density was significantly reduced by $40 \%(P<0.049)$ and $61 \%(P<0.007)$ for the two treatments where $C$. rosea IK726 was applied during imbibition followed by incubation at 40 and $38 \% \mathrm{MC}$, respectively. When $C$. rosea IK726 was applied after the imbibition, seed drying did not result in a significant decrease in population density (Figs. 6 and 7). During storage at $4^{\circ} \mathrm{C}$, the CFU per seed gradually decreased (Fig. 7). After 37 weeks, the population density was significantly reduced to $29 \%$ of the density at the beginning of storage of seed in which $C$. rosea IK726 was applied to seed at $40 \% \mathrm{MC}(P<0.009)$, and by $26 \%(P<0.002)$ and $40 \%(P<0.045)$ for the two treatments in which $C$. rosea IK726 was applied during imbibition followed by incubation at 40 and $38 \%$ MC, respectively.

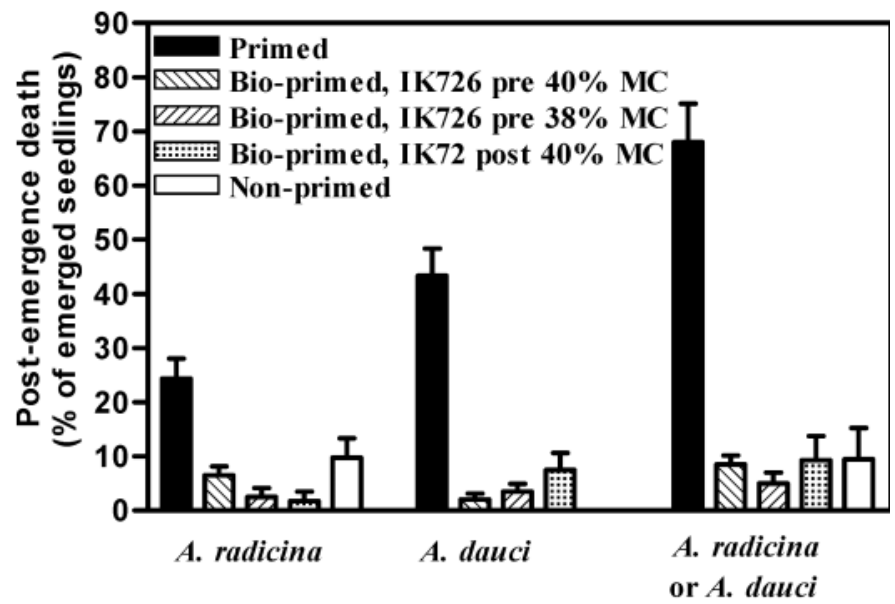

\section{Pathogen}

Fig. 4. Effect of priming and biopriming with Clonostachys rosea IK726 on postemergence death of carrot seedlings caused by Alternaria radicina or $A$. dauci. Isolate IK726 was either applied at imbibition, before drying seeds to 38 or $40 \%$ moisture content (MC), or after imbibition but postdrying seeds to $40 \%$ MC. Before storage, seeds were dried to $8 \%$ MC. Error bars indicate standard errors of the means of four replicates.

TABLE 2. Effect of various priming treatments on total seedling emergence and final stand of healthy carrot seedlings after several days of priming

\begin{tabular}{|c|c|c|c|c|c|c|c|c|}
\hline \multirow[b]{3}{*}{ Treatment } & \multicolumn{8}{|c|}{ Seedling emergence $(\%)$} \\
\hline & \multicolumn{2}{|c|}{ Nonprimed } & \multicolumn{2}{|c|}{ Priming 1 day } & \multicolumn{2}{|c|}{ Priming 8 days } & \multicolumn{2}{|c|}{ Priming 14 days } \\
\hline & Total $^{\mathrm{t}}$ & Healthy ${ }^{\mathrm{u}}$ & Total & Healthy & Total & Healthy & Total & Healthy \\
\hline Hydroprimed, $40 \% \mathrm{MC}^{\mathrm{v}}$ & 43.0 & 37.7 & $44.5 \mathrm{a}^{\mathrm{w}}$ & $32.5 \mathrm{a}$ & $22.0 \mathrm{a}$ & $0.5 \mathrm{a}$ & $30.0 \mathrm{a}$ & $6.7 \mathrm{a}$ \\
\hline Bioprimed, Clonostachys rosea $\mathrm{IK} 726$ pre- $40 \% \mathrm{MC}^{\mathrm{x}}$ & 43.0 & 37.7 & $62.6 \mathrm{a}$ & $58.7 \mathrm{~b}$ & $62.0 \mathrm{~b}$ & $59.0 \mathrm{~b}$ & $54.0 \mathrm{bc}$ & $52.0 \mathrm{bc}$ \\
\hline Bioprimed, C. rosea IK726 pre-38\% MC & 43.0 & 37.7 & $58.5 \mathrm{a}$ & $53.5 \mathrm{~b}$ & $62.0 \mathrm{~b}$ & $59.0 \mathrm{~b}$ & $59.0 \mathrm{c}$ & $56.0 \mathrm{c}$ \\
\hline Bioprimed, C. rosea IK 726 post- $40 \% \mathrm{MC}^{\mathrm{z}}$ & 43.0 & 37.7 & $59.5 \mathrm{a}$ & $56.5 \mathrm{~b}$ & $56.0 \mathrm{~b}$ & $52.0 \mathrm{~b}$ & $46.0 \mathrm{~b}$ & $43.5 \mathrm{~b}$ \\
\hline$P$ value & & & 0.0847 & 0.0029 & 0.0001 & 0.0002 & 0.0002 & 0.0001 \\
\hline \multicolumn{9}{|c|}{$\begin{array}{l}\text { Total seedling emergence. } \\
\text { u Final stand of healthy seedlings. Wilted and dead seedlings infected by Alternaria radicina or } \text { A. dauci were excluded. } \\
{ }^{\mathrm{v}} \text { Seeds were imbibed in aerated water ( } 50 \mathrm{~g} \text { of seed per } 500 \mathrm{ml} \text { of water) for } 16 \mathrm{~h} \text {, dried to a predetermined moisture content (MC) of } 40 \% \text {, and subsequently } \\
\text { incubated at } 15^{\circ} \mathrm{C} \text {. For biopriming, the method was modified as specified. }\end{array}$} \\
\hline \multicolumn{9}{|c|}{$\begin{array}{l}\text { w In each column, means of four replicates followed by different letters differ significantly according to an } F \text {-protected least significant difference test at } P=0.05 \text {. } \\
\text { The actual } P \text { value is given below each column. }\end{array}$} \\
\hline \multicolumn{9}{|c|}{${ }^{x}$ Clay inoculum of $C$. rosea IK 726 was applied at imbibition of seeds ( $2.5 \mathrm{~g}$ of clay inoculum per $500 \mathrm{ml}$ of water) before drying seeds to $40 \%$ MC. } \\
\hline \multicolumn{9}{|c|}{ y Clay inoculum of $C$. rosea IK726 was applied at imbibition of seeds ( $2.5 \mathrm{~g}$ of clay inoculum per $500 \mathrm{ml}$ of water) before drying seeds to $38 \%$ MC. } \\
\hline
\end{tabular}


Microscopic evaluation of seed during priming. The development and establishment of $C$. rosea IK726d11 during biopriming of carrot seeds was investigated by fluorescence microscopy. The increase in mycelial growth and sporulation on the seed surface from day 1 to day 14 is visualized in Figure 8A to I. Discrete fluorescent aggregates, mainly associated with peat-bran particles, were visible on seed treated with $C$. rosea IK726d11 on day 0 and day 1 (Fig. 8A). Hyphal growth from some of the
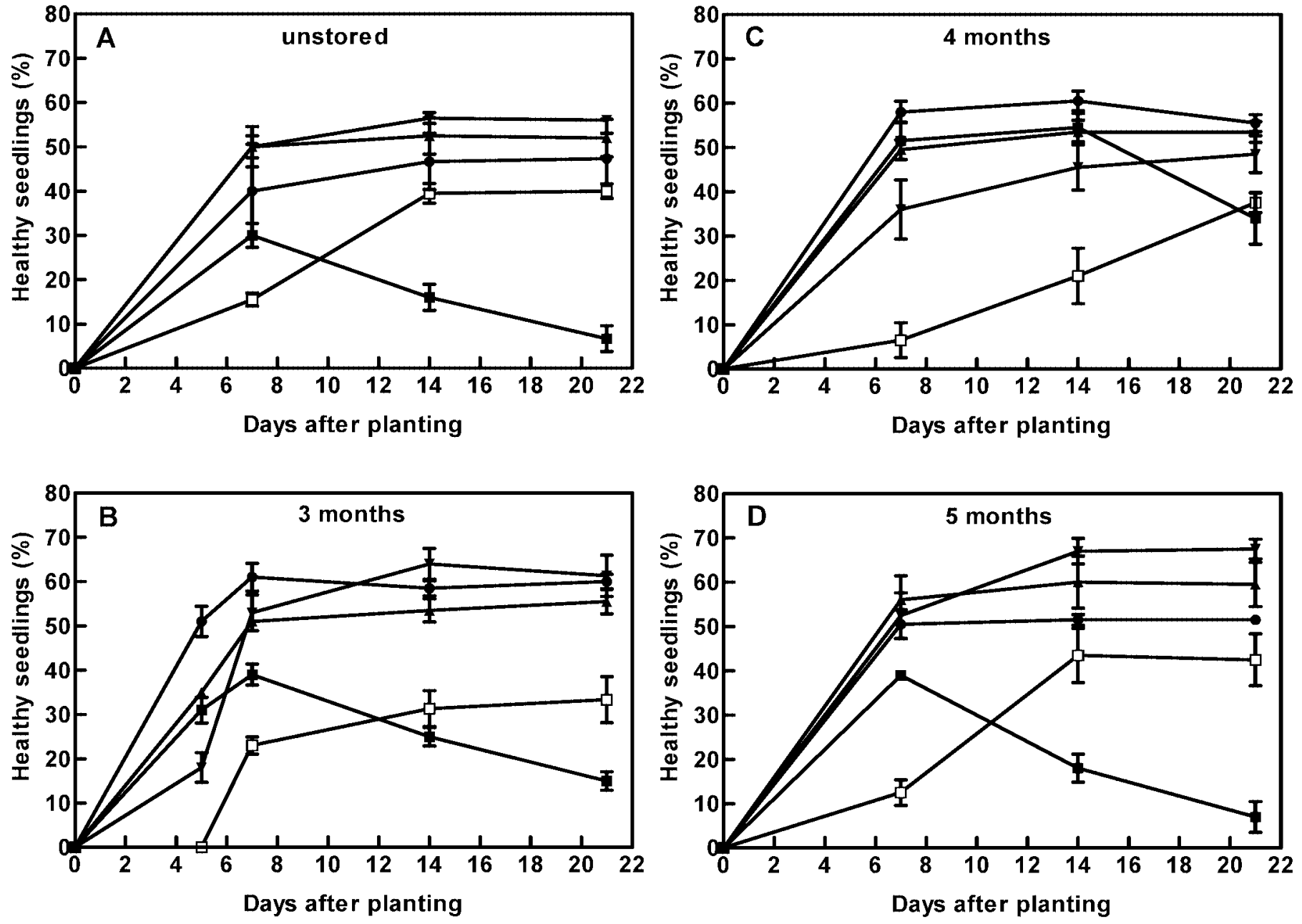

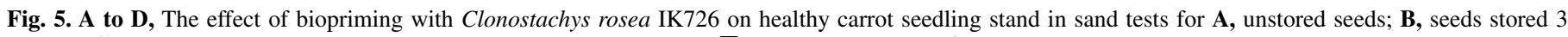

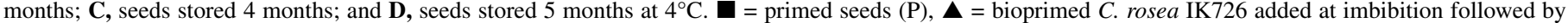

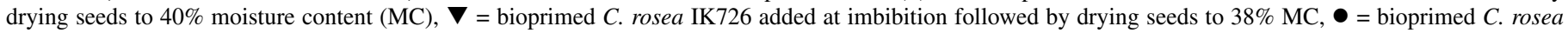
IK726 added after imbibition and drying seeds to $40 \% \mathrm{MC}$, and $\square=$ nonprimed seeds. Error bars indicate standard errors of the means of four replicates.

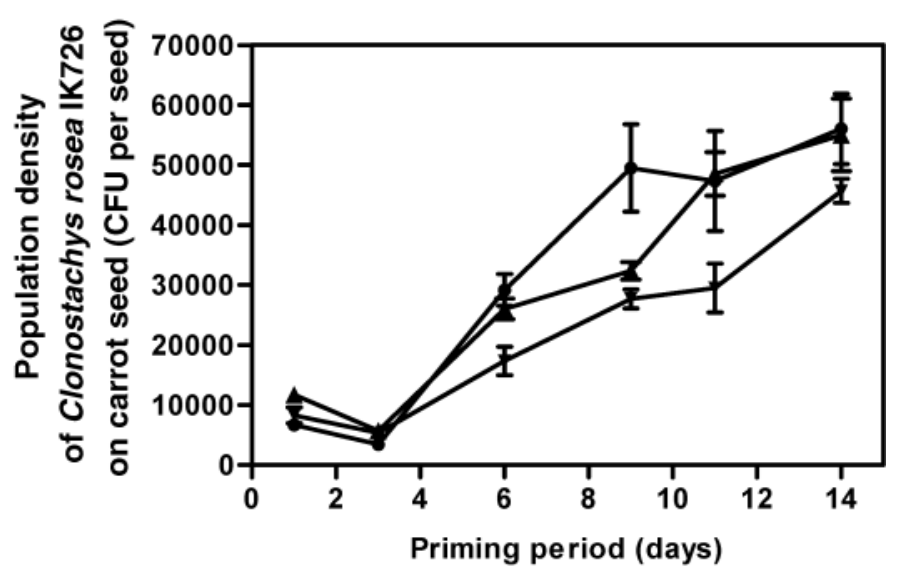

Fig. 6. Multiplication of Clonostachys rosea IK726 on carrot seed during biopriming at $15^{\circ} \mathrm{C} . \boldsymbol{\Delta}=$ bioprimed $C$. rosea $\mathrm{IK} 726$ added at imbibition before drying seeds to $40 \%$ moisture content (MC), $\boldsymbol{\nabla}=$ bioprimed $C$. rosea IK726 added at imbibition followed by drying seeds to $38 \% \mathrm{MC}$, and $\bullet=$ bioprimed $C$. rosea IK726 added after imbibition and drying seeds to $40 \%$ MC. Error bars indicate standard errors of the means of three replicates.

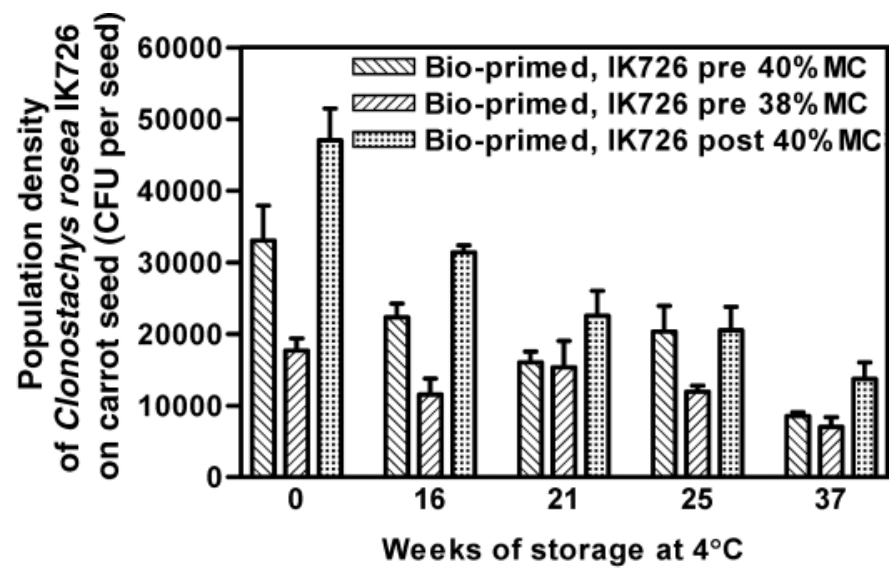

Fig. 7. Survival of Clonostachys rosea IK726 during storage of bioprimed seeds at $4{ }^{\circ} \mathrm{C}$. Isolate IK 726 was applied either at imbibition before (pre) drying seeds to 38 and $40 \%$ moisture content (MC) or after imbibition and drying seeds (post) to $40 \%$ MC. Primed seeds were dried to $8 \% \mathrm{MC}$ before storage. Error bars represent standard errors of the means of three replicates. 

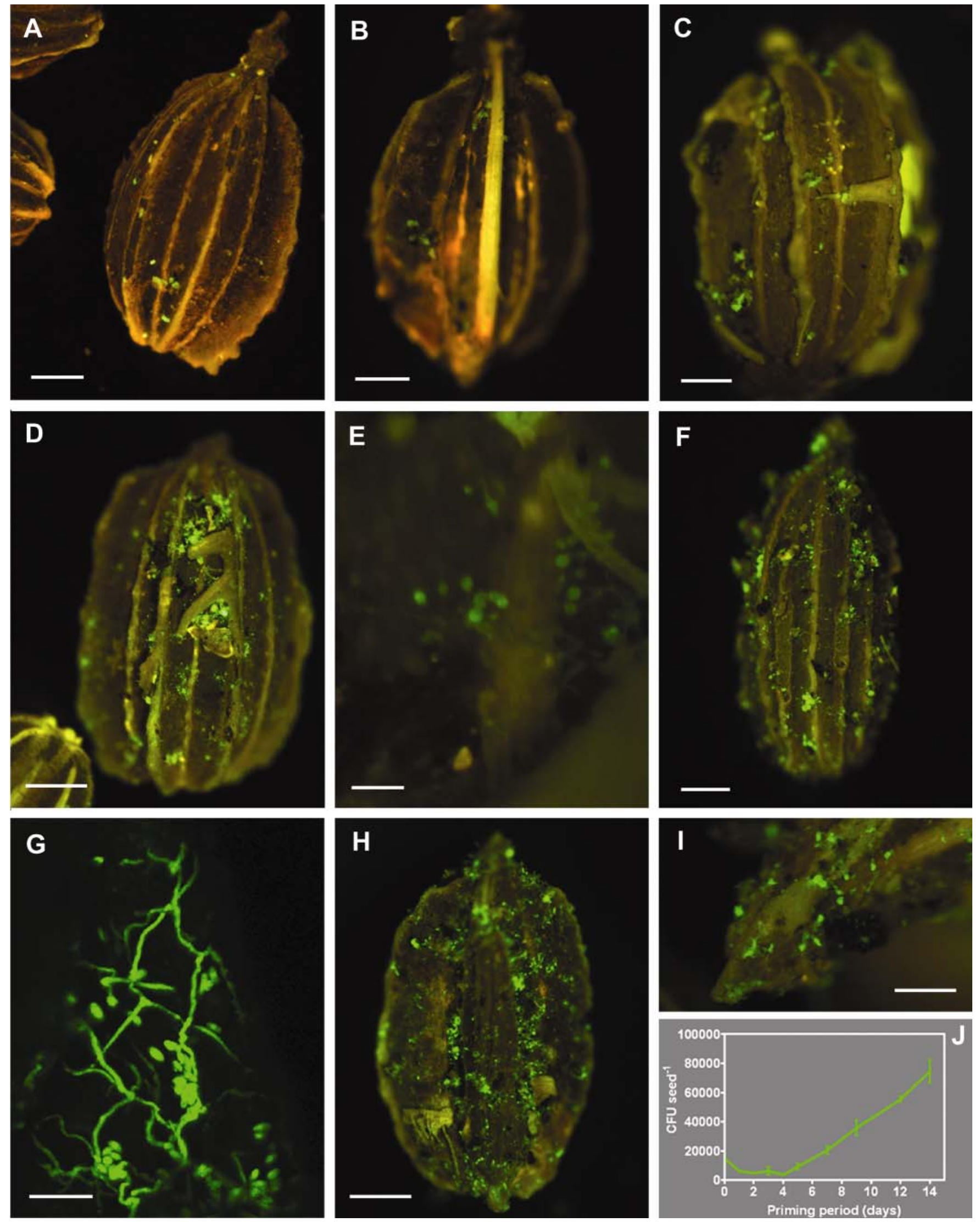

Fig. 8. Development and establishment of the $g f p$ transformant Clonostachys rosea $\mathrm{IK} 726 \mathrm{~d} 11$ on carrot seed during biopriming at $15^{\circ} \mathrm{C}$ studied with stereo fluorescence microscopy (SFM) and confocal laser scanning microscopy (CLSM). Growth of isolate IK726d11 was visualized with SFM on seeds after a biopriming period of A, 1 day; $\mathbf{B}, 2$ days; $\mathbf{C}, 3$ days; $\mathbf{D}, 5$ days; $\mathbf{F}, 7$ days; and $\mathbf{H}, 14$ days. $\mathbf{E}$, Sporulation with verticilliate conidiophores was observed after 4 to 5 days. I, Penicilliate conidiophores were observed after 6 days. G, With CLSM, a fine web of hyphae was seen on the pericarp at day 7. J, The development in density of C. rosea IK726d11 on seeds (CFU/seed) was observed during biopriming. Error bars represent standard errors of the mean of three replicates. A, B, C, $\mathbf{D}, \mathbf{F}$, and $\mathbf{H}$, Bars represent $250 \mu \mathrm{m} ; \mathbf{I}, 100 \mu \mathrm{m} ; \mathbf{E}, 50 \mu \mathrm{m} ;$ and $\mathbf{G}, 20 \mu \mathrm{m}$. 
aggregates was observed with an SFM after 2 days. Conidial germination and the presence of fine hyphae scattered on the pericarp were verified with an EFM. Sporulation, with verticilliate conidiophores, was observed from day 4 to 5 and onward (Fig. $8 \mathrm{E})$. The intensity of sporulation was increased on the following days, which corresponded with a significant $(P<0.001)$ increase in CFU per seed (Fig. 8J). From day 7, a fine web of mycelium could be seen (Fig. 8F and G) and at the end of priming penicilliate, and verticilliate conidiophores covered the whole seed surface (Fig. $8 \mathrm{H}$ to I). Fungal growth was also present at the micropylar end of the seed where the radicle and shoot protrude from the pericarp (Fig. 8I). Background fluorescence from the wild-type $C$. rosea or from the untreated primed seeds was generally not confounded with the fluorescence emitted from C. rosea $\mathrm{IK} 726 \mathrm{~d} 11$.

\section{DISCUSSION}

Several antagonistic isolates effective against seedborne $A$. radicina and $A$. dauci were identified after in planta screening of fungi isolated from cereal and carrot habitats. Isolates from the cereal group were selected from a group of isolates representing different genera that previously showed a biocontrol efficacy of $>50 \%$ against seedborne $F$. culmorum in sand tests (21). Isolates from the carrot group were obtained from different carrot-related material. For both groups, isolates belonging to $C$. rosea, in general, had a very high biocontrol efficacy. Moreover, in both isolate groups (not shown for carrot isolates), isolates having a level of efficacy equal to the fungicide iprodione on $A$. radicinainfested seeds belonged to C. rosea, Gliocladium spp., or Clonostachys spp. sensu stricto. The overlap in effective antagonistic species between isolates from cereal and from carrot habitats might be related to similarities in infection biology of the pathogens that the isolates are aimed to control. Seedborne $A$. radicina and $A$. dauci are generally superficially located in or on the pericarp $(37,38)$ and infect the seedling through the hypocotyls, as does the cereal seedborne pathogen $F$. culmorum $(27,32)$. The biocontrol potential of $C$. rosea has been shown in several systems. In the field, $C$. rosea isolate IK726 had high efficacy against three seedborne cereal diseases caused by $F$. culmorum, Bipolaris sorokiniana, and Tilletia tritici, respectively $(17,18,22)$. The isolate also has exhibited effective control against $A$. radicina in growth chamber experiments (26).

Priming strongly increased the incidence of Alternaria spp. In agreement with our results, hydropriming increased the incidence of A. dauci, A. radicina, and A. alternata on carrot seed (40). Baniek and Tylkowska (1) showed that osmopriming increased the general microflora, although the level of A. radicina was unaffected or even decreased. On the other hand, Nascimento and West (31) reported that osmopriming increased Alternaria spp. on melon seeds from 2 to $50 \%$. Maude et al. (29), however, concluded that osmopriming did not affect the rate of transmission of A. dauci. The different effects of priming on the occurrence of Alternaria spp. is probably related to both differences in priming procedures as well as location and incidence of the pathogens of the seed lots. In the present study, the enhanced growth of $A$. dauci and $A$. radicina during priming could primarily explain the large reduction in final stand of healthy seedlings compared with that of nonprimed seeds. In contrast, biopriming almost eradicated the two pathogens, which lead to a highly improved seedling stand that was significantly higher than that of nonprimed seeds.

Based on dilution plating of bioprimed seed, the population density of $C$. rosea IK726 increased significantly from about $1 \times$ $10^{4} \mathrm{CFU}$ per seed to 3 to $5 \times 10^{4} \mathrm{CFU}$ per seed, irrespective of the application method. In replicated experiments with bioprimed seeds at 38 to $40 \% \mathrm{MC}$, the final density never exceeded $8 \times$ $10^{4} \mathrm{CFU}$ per seed, which seemed to be the limit for multiplication of C. rosea IK726 on carrot seeds. Data on multiplication of fungi on seed during biopriming are limited. However, Harman and Taylor (10) found that T. harzianum strain T-22 increased 10-fold to a level of $10^{4} \mathrm{CFU}$ per seed during matrix priming of tomato and cucumber seed. In this study, the temporary decrease in population density observed after 2 to 3 days of priming coincides with the time of conidial germination and hyphal growth of C. rosea IK726 as verified with fluorescent microscopy. A similar relationship was found for T. harzianum when conidia of the antagonist were introduced to growth medium (9). Based on microscopic evaluation of the growth and distribution of the antagonist during priming, $C$. rosea IK $726 \mathrm{~d} 11$ colonized the whole surface of the pericarp, including the apex of the seed where the primary root emerges. This is of course important for protecting the seedling against inoculum of pathogenic Alternaria spp. as well as other seedborne pathogens located on or in the pericarp. Furthermore, it provides an opportunity to protect the seedling from soilborne pathogens attacking the emerging seedling. In preliminary experiments with carrot, $C$. rosea IK726 biopriming reduced seedling damping-off caused by Pythium ultimum mixed in the growing media (B. Jensen, unpublished data), and in field experiments, spraying with $C$. rosea IK726 conidia reduced leaf and head rot of Chinese cabbage caused by Pythium tracheiphilum (30).

In the present study, we used a water priming technique to imbibe seeds and subsequently dried them to a predetermined MC. The application of antagonists was made either during imbibition or after the seeds were dried to the predetermined MC. By the latter method, considerably less material of the BCA $(<1 / 3)$ was applied. At the same time, the efficacy against the seedborne pathogens was approximately equal for the two priming methods. Furthermore, the waste water from the priming process was not contaminated with the antagonist. Application of $C$. rosea IK726 after drying seeds, therefore, seems to be a more economically and environmentally feasible biopriming procedure. Except for the method of adjusting seeds to a predetermined MC, the priming method used in the present experiments very much resembles the drum-priming technique used commercially (36). C. rosea IK726 may therefore be a potential candidate for biopriming in practice.

The results of priming two seed lots with a high and a low level of natural infection with Alternaria pathogens indicated that A. dauci occurred at higher levels than A. radicina after application of the hydropriming technique used in the present study. Based on examination of diseased seedlings after emergence, about twothirds of these seedlings were infected with A. dauci. Because the contamination level for $A$. dauci was lower than that for A. radicina at the beginning, this further indicates that $A$. dauci develops more efficiently on primed seed. Data on the occurrence of Alternaria spp. immediately after the imbibition previously showed that this process increased spread of conidia within the seed lot (20). Tylkowska and Van den Bulk (40) hydroprimed two carrot seed lots using a laboratory technique imitating drum priming (36), but did not find that $A$. dauci was favored in particular. This could be related to the different imbibition procedures for the two hydropriming methods.

In this study, we demonstrate that biopriming with the biocontrol strain $C$. rosea isolate IK726 makes it possible to prime seeds infected with pathogenic Alternaria spp. without risking adverse effects on seedling establishment. This is particularly interesting for organic farmers because it is difficult to produce high quality disease-free seed organically.

\section{ACKNOWLEDGMENTS}

The project was funded by The Danish Ministry of Food, Agriculture and Fisheries and the Quality of Life programme, Key action 1, of the EU Fifth Framework programme (project Safe Organic Vegetables, QLK1- 
1999-00986). We thank L. Daehnfeldt A/S for delivering seed lots and K. Olesen for skillful technical assistance.

\section{LITERATURE CITED}

1. Baniek, A., and Tylkowska, K. 1987. Germination and mycoflora of carrot seeds treated with thiram and conditioned in polyethylene glycol (PEG 6000). Acta Hortic. 215:225-230.

2. Ben-Noon, E., Shtienberg, D., Shlevin, E., Vintal, H., and Dinoor, A. 2001. Optimization of chemical suppression of Alternaria dauci, the causal agent of Alternaria leaf blight in carrots. Plant Dis. 85:1149-1156.

3. Bochow, H. 1992. Phytosanitary effects of Bacillus subtilis as biocontrol agent. Med. Fac. Landbouw. Univ. Gent 57/2b:387-393.

4. Brocklehurst, P. A., and Dearman, J. 1983. Interactions between seed priming treatments and nine seed lots of carrot, celery and onion. II. Seedling emergence and plant growth. Ann. Appl. Biol. 102:585-593.

5. Callan, N. W., Mathre, D. E., and Miller, J. B. 1990. Bio-priming seed treatment for biological control of Pythium ultimum preemergence damping-off in $s h 2$ sweet corn. Plant Dis. 74:368-372.

6. Callan, N. W., Mathre, D. E., and Miller, J. B. 1991. Yield performance of sweet corn seed bioprimed and coated with Pseudomonas fluorescens AB254. HortScience 26:1163-1165.

7. Chen, T. W., and Wu, W. S. 1999. Biological control of carrot black rot. J. Phytopathol. 147:99-104.

8. Finch-Savage, W. E. 1990. The effect of osmotic seed priming and the timing of water availability in the seedbed on the predictability of carrot seedling establishment in the field. Acta Hortic. 267:209-216.

9. Green, H., and Jensen, D. F. 1995. A tool for monitoring Trichoderma harzianum: GUS transformants used for ecological studies in the rhizosphere. Phytopathology 85:1436-1440.

10. Harman, G. E., and Taylor, A. G. 1988. Improved seedling performance by integration of biological control agents at favorable $\mathrm{pH}$ with solid matrix priming. Phytopathology 78:520-525.

11. Harman, G. E., Taylor, A. G., and Stasz, T. E. 1989. Combining effective strains of Trichoderma harzianum and solid matrix priming to improve biological seed treatment. Phytopathology 73:631-637.

12. Hermansen, A., Brodal, G., and Balvoll, G. 1999. Hot water treatments of carrot seeds: Effects on seed-borne fungi, germination, emergence and yield. Seed Sci. Technol. 27:599-613.

13. Hökeberg, M., Gerhardson, B., and Johnsson, L. 1997. Biological control of cereal seed-borne diseases by seed bacterization with green-houseselected bacteria. Eur. J. Plant Pathol. 103:25-33.

14. ISTA. 1996. International Rules for Seed Testing, 1996. Seed Sci. Technol. Suppl. 24

15. Jahn, M., and Puls, A. 1998. Investigations for development of a combined biological-physical method to control soilborne and seed-borne pathogens in carrot seed. J. Plant Dis. Prot. 105:359-375.

16. Jamal, E., Bochow, H., and Hentschel, K. D. 1993. Bacillus subtilis and chemical seed dressing about equally effective in suitable environment. Gartenbau-magazin 2:38-39

17. Jensen, B., Jensen, D. F., Nielsen, G. C., and Nielsen, B. J. 2001. Biological seed treatment to control seed borne diseases in wheat. Conference Biological and Microbial Control of Pests. DJF-rapport 49:51-56.

18. Jensen, B., Knudsen, I. M. B., and Jensen, D. F. 2000. Biological seed treatment of cereals with fresh and long term stored formulations of Clonostachys rosea: Biocontrol efficacy against Fusarium culmorum. Eur. J. Plant Pathol. 106:233-242.

19. Jensen, B., Knudsen, I. M. B., and Jensen, D. F. 2002. Survival of conidia of Clonostachys rosea coated on barley seeds and their biocontrol efficacy against seed-borne Bipolaris sorokiniana. Biocontrol Sci. Technol. 12:427-441.

20. Jensen, B., Poulsen, F. V., Knudsen, I. M. B., and Jensen, D. F. 2001. Combining microbial seed treatment with priming of carrot seeds for control of seed borne Alternaria spp. IOBC/WPRS Bull. 24:197-201.
21. Knudsen, I. M. B., Hockenhull, J., and Jensen, D. F. 1992. In vivo screening of potential antagonists against $F$. culmorum in barley. IOBC/WPRS Bull. 15:21-23.

22. Knudsen, I. M. B., Hockenhull, J., and Jensen, D. F. 1995. Biocontrol of seedling diseases of barley and wheat caused by Fusarium culmorum and Bipolaris sorokiniana: Effects of selected fungal antagonists on growth and yield components. Plant Pathol. 44:467-477.

23. Knudsen, I. M. B., Hockenhull, J., Jensen, D. F., Gerhardson, B. Hökeberg, M., Tahvonen, R., Teperi, E., Sundheim, L., and Henriksen, B. 1997. Selection of biological control agents for controlling soil- and seedborne pathogens in the field. Eur. J. Plant Pathol. 103:775-784.

24. Kreger-van-Rij, N. J. W. 1984. The Yeasts: A Taxonomic Study. Elsevier Science Publishing, Amsterdam.

25. Lauritzen, J. L. 1926. The relation of black rot to the storage of carrots. J. Agric. Res. 33:1025-1041.

26. Lübeck, M., Knudsen, I. M. B, Jensen, B., Thrane, U., Janvier, C., and Jensen, D. F. 2002. GUS and GFP transformation of the biocontrol strain Clonostachys rosea IK726 and the use of these marker genes in ecological studies. Mycol. Res. 106:815-826.

27. Malalasekera, R. A. P., Sanderson, F. R., and Colhoun, J. 1973. Fusarium diseases of cereals. IX. Penetration and invasion of wheat seedlings by Fusarium culmorum and F. nivale. Trans. Br. Mycol. Soc. 60:453-462.

28. Maude, R. B. 1966. Studies on the etiology of black rot, Stemphylium radicinum (Meier, Drechsl. \& Eddy) Neerg., and leaf blight, Alternaria dauci (Kühn) Grovers \& Skolko, on carrot crops; and on fungicide control of their seed-borne infection phases. Ann. Appl. Biol. 57:83-93.

29. Maude, R. B., Drew, R. L. K., Gray, D., Petch, G. M., Bujalski, W., and Nienow, A. W. 1992. Strategies for control of seed-borne Alternaria dauci (leaf blight) of carrots in priming and process engineering systems. Plant Pathol. 41:204-214

30. Møller, K., Jensen, B., Andersen, H. P., Stryhn, H., and Hockenhull, J. 2003. Biocontrol of Pythium tracheiphilum in Chinese cabbage by Clonostachys rosea under field conditions. Biocontrol Sci. Technol. 13:171182.

31. Nascimento, W. M., and West, S. H. 1998. Microorganism growth during muskmelon priming. Seed Sci. Technol. 26:531-534.

32. Neergaard, P. 1979. Seed Pathology, Volume I. Macmillan Press, London.

33. Nirenberg, H. J. 1976. A simplified method for identifying Fusarium spp. occurring on wheat. Can. J. Bot. 50:1599-1609.

34. Pryor, B. M., Davis, R. M., and Gilbertson, R. L. 1994. Detection and eradication of Alternaria radicina on carrot seed. Plant Dis. 78:452-456.

35. Pryor, B. M., Davis, R. M., and Gilbertson, R. L. 1998. Detection of soilborne Alternaria radicina and its occurrence in California carrot fields. Plant Dis. 82:891-895.

36. Rowse, H. R. 1996. Drum priming - an environmentally friendly way of improving seed performance. J. R. Agric. Soc. England 157:77-83.

37. Soteros, J. J. 1979. Detection of Alternaria radicina and A. dauci from imported carrot seed in New Zealand. N.Z. J. Agric. Res. 22:185-190.

38. Strandberg, J. O. 1983. Infection and colonization of inflorescences and nericarps of carrot by Alternaria dauci. Plant Dis. 67:1351-1353.

39. Strandberg, J. O. 1984. Efficacy of fungicides against persistence of Alternaria dauci on carrot seed. Plant Dis. 68:39-42.

40. Tylkowska, K., and Van den Bulk, R. W. 2001. Effects of osmo- and hydropriming on fungal infestation levels and germination of carrot (Daucus carota L.) seeds contaminated with Alternaria spp. Seed Sci. Technol. 29:365-375.

41. Van den Bulk, R. W., and Langerak, C. J. 1995. Application of seed health testing at various stages of the seed production chain. Pages 101112 in: Proc. ISTA Pre-Congress Seminar on Seed Pathol. International Seed Testing Association (ISTA), Zurich, Switzerland.

42. Warren, J. E., and Bennett, M. A. 1999. Bio-osmopriming tomato (Lycopersicon esculentum Mill.) seeds for improved stand establishment. Seed Sci. Technol. 27:489-499. 